\title{
How can low-pressure channels and deforming tills coexist subglacially?
}

\author{
Richard B. Alley \\ Earth System Science Center and Department of Geosciences, The Pennsylvania State University, \\ University Park, Pennsylvania 16802, U.S.A.
}

\begin{abstract}
Deforming till and low-pressure water channels are observed to coexist subglacially, but till also is observed to creep rapidly into low-pressure subglacial regions. A simple model shows that these observations are not contradictory. Creep of a thin till to a low-pressure region can occur from a narrow zone only, and will lead to isolation of channels from till farther away.
\end{abstract}

\section{INTRODUCTION}

Creep of till at a rate of $0.2 \mathrm{md}^{-1}$ into a tunnel dug beneath a glacier was observed by Boulton (1976), leading Boulton and Hindmarsh (1987) to suggest that the creep of till into subglacial streams and transport in the streams could be an effective mechanism for removing sediment from beneath glaciers. Yet, Engelhardt and others (1978; also see Meier, 1989) observed deforming till and low-pressure channels in close proximity subglacially, showing that the channels had not removed all of the deforming sediment. Here I use a simple model to argue that the rapid, non-steady creep of till to a channel observed by Boulton (1976) can affect a thin till between ice and bedrock only within a short distance of the channel, so that the coexistence of low-pressure channels and soft subglacial sediments observed by Engelhardt and others (1978) is not surprising.

\section{MODELS FOR TILL CREEP TO CHANNELS}

I conduct an order-of-magnitude analysis here. Assumptions and sources of error are considered in the discussion below.

The assumed geometry is shown in Figure 1. Ice with basal pressure $P_{\mathrm{i}}$ overlies a thin till of thickness $h$, penetrated by a channel with pressure $P_{\mathrm{w}}<P_{\mathrm{i}}$, all resting on rigid bedrock. Till is modeled by one of three continuum approximations: perfect plasticity, linear viscosity and Bingham rheology.

I follow Turcotte and Schubert (1982, p. 234) in adopting a pseudo-hydrostatic model (neglecting deviatoric stresses) characterized by a pressure, $P$, in the continuum till, with flow of the bulk till driven by spatial gradients in $P$. Clearly, at the microscopic scale the bulk till consists of grains and pores, with a pore-water pressure, $P_{\mathrm{p}}$, typically less than $P$ (and clast-clast contact pressures correspondingly greater than $P$ ). The flow properties of the till probably vary with $P-P_{\mathrm{p}} \equiv N$, and spatial gradients in $P_{\mathrm{p}}$ may cause pore-water flow through the

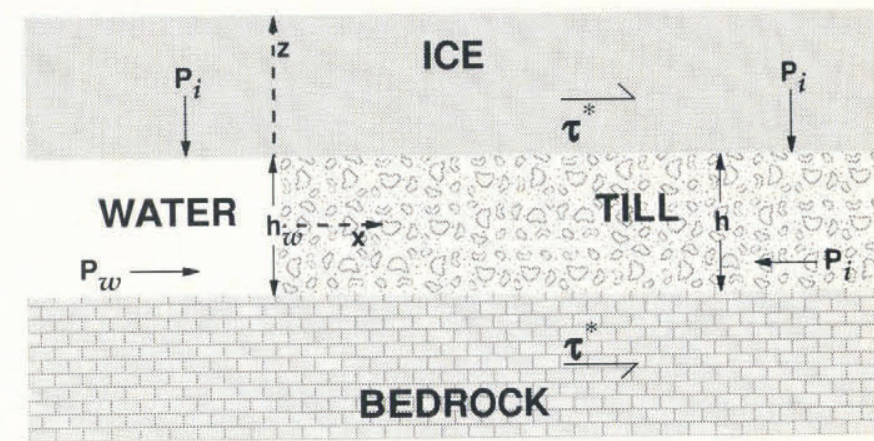

Fig. 1. Cartoon of the geometry for models developed here. Variables are defined in the text.

till in addition to any water advection with the deforming till (cf. Clarke, 1987).

Far from the channel the till supports the full weight of the ice and has pressure $P=P_{\mathrm{i}}$, and at the channel the till pressure drops to $P=P_{\mathrm{w}}$. Till creep is assumed to occur to the channel, driven by the pressure difference $P_{\mathrm{i}}-P_{\mathrm{w}}$ along the till, and is resisted by the yield strength or viscosity of the till. I then solve for the maximum distance from which (significant) creep can occur.

\section{Perfect-plasticity model}

The coordinate system shown in Figure 1 has its origin at the vertical midpoint of the till-channel face, with $+x$ normal to that face away from the channel and $+z$ vertically upward. Per unit length along the channel (out of the page in Figure 1), the force causing till creep is $F_{\mathrm{c}}=\left(P_{\mathrm{i}}-P_{\mathrm{w}}\right) h_{\mathrm{w}}$, where $h_{\mathrm{w}}$ is the till thickness in contact with the channel; the force resisting creep is $F_{\mathrm{r}}=2 \tau^{*} x^{*}$, where $\tau^{*}$ is the till yield strength. The distance $x^{*}$ is the maximum till catchment length; creep may occur from a distance less than $x^{*}$, but cannot occur from $x>x^{*}$. The factor of 2 in the expression for $F_{\mathrm{r}}$ arises because creep occurs past upper and lower surfaces of the till. 
To estimate $x^{*}$, I invoke force balance, equate $F_{\mathrm{c}}$ and $F_{\mathrm{r}}$, and solve to obtain

$$
x^{*}=\frac{\left(P_{\mathrm{i}}-P_{\mathrm{w}}\right) h_{\mathrm{w}}}{2 \tau^{*}} .
$$

The yield strength, $\tau^{*}$, can be approximated as (e.g. Boulton and Hindmarsh, 1987)

$$
\tau^{*}=N \tan \phi+C
$$

where $\tan \phi$ is the internal friction and $C$ is the cohesion of the till; $N$ is the difference between the bulk pressure, $P$, and the pore-water pressure in the till, $P_{\mathrm{p}}$. In earlier papers (e.g. Alley, 1989a; and based on Boulton and others (1974)) I have suggested that $C=4 \mathrm{kPa}$, $\tan \phi=0.2$ are possible values for a typical till undergoing deformation from the basal shear stress of the ice, and I adopt these values here for till creep to a channel. (The observation of till deformation beneath a variety of glaciers (e.g. Engelhardt and others, 1978; Boulton and Hindmarsh, 1987; Blake and Clarke, 1989; Meier, 1989) demonstrates that values of $C$ and $\tan \phi$ are toward the low end of those typically reported in the soils literature (Alley and others, 1987a).)

The effective pressure, $N$, should approach zero at the channel, $x=0$, where the boundary condition is $P=P_{\mathrm{p}}=P_{\mathrm{w}}$. The pore-water pressure, $P_{\mathrm{p}}$, will rise away from the channel, reaching a value at the divide with the next channel that depends on the till permeability and thickness, the water supply and the channel spacing, but which will not exceed the Weertman-film value of a few tenths of a bar less than $P_{\mathrm{i}}$ (Weertman, 1972). Shoemaker (1986) showed that for typical deforming-till permeabilities and other factors, introduction of a lowpressure channel will rapidly reduce pore-water pressures significantly below the Weertman-film value in a zone tens to hundreds of meters wide, causing $P_{\mathrm{p}}$ to be almost as low as $P_{\mathrm{w}}$ within a few meters of the channel. Below, I show that if till has a significant yield strength or viscosity, its pressure, $P$, rises steeply away from a channel and approaches or equals $P_{\mathrm{i}}$ only a few meters from the channel, giving $N \approx P_{\mathrm{i}}-P_{\mathrm{w}}$ at the limit of till creep, $x=x^{*}$. As a crude approximation (see discussion), I assume that $N$ is constant at the average of the extreme values at $x=0$ and $x=x^{*}$, or

$$
N=\frac{1}{2}\left(P_{\mathrm{i}}-P_{\mathrm{w}}\right) \text {. }
$$

The value of $P_{\mathrm{w}}$ probably depends on both ice-water and sediment-water interactions (Walder and Fowler, 1989), but for simplicity I will estimate $P_{\mathrm{w}}$ from the theory of Röthlisberger channels (Röthlisberger, 1972; Weertman, 1972), assuming that the channel is waterfilled and the ice-water interaction controls channel pressure. (Notice that if $P_{\mathrm{w}}<P_{\mathrm{i}}$ there is a tendency for till creep to the channel, regardless of the physical processes that control $P_{\mathrm{w}}$.) If channel radii and potential gradients driving channel flow are not too small $(>\approx 0.1 \mathrm{~m}$, $>\approx 10 \mathrm{~Pa} \mathrm{~m}^{-1}$, then

$$
\left(P_{\mathrm{i}}-P_{\mathrm{w}}\right) \tan \phi \gg C
$$

and combining this with Equations (2) and (3)

$$
\tau^{*} \approx \frac{1}{2}\left(P_{\mathrm{i}}-P_{\mathrm{w}}\right) \tan \phi
$$

Substituting for $\tau^{*}$ in Equation (1) from Equation (5) for the initial configuration of Figure 1 with $\tan \phi=0.2$ yields

$$
\begin{gathered}
x^{*} \approx \frac{h_{\mathrm{w}}}{\tan \phi} \\
x^{*} \approx 5 h_{\mathrm{w}} .
\end{gathered}
$$

Thus, the simple result is that a perfectly plastic till layer with $\tan \phi=0.2$ and yield strength given by Equation (5) can creep toward a low-pressure channel through thickness $h_{\mathrm{w}}$ from a catchment area of half-width no greater than $x^{*} \approx 5 h_{\mathrm{w}}$. For $h_{\mathrm{w}}=0.1$ to $1 \mathrm{~m}, x^{*} \approx 0.5$ to $5 \mathrm{~m}$, a short distance.

\section{Time-dependent solution}

The perfect-plasticity analysis assumes a yield strength for creep to a channel, but that yield strength may be reduced or eliminated if subglacial till is sheared along ice flow by the basal shear stress of the ice, as seems likely in many cases (but see discussion). If so, then the perfect-plasticity limit on the till catchment area is broadened or eliminated. However, I show next that by including likely till viscosities, the catchment area for significant creep remains narrow even in the limit of zero yield strength. I also estimate the time-scale for thinning of till adjacent to channels, and find that it is on the order of 1 year or less.

The Bingham relation for sediment deformation in the coordinate system of Figure 1 is

$$
\begin{array}{lll}
\frac{\partial u}{\partial z}=\frac{1}{\mu}\left(\tau \pm \tau^{*}\right), & & |\tau|>\tau^{*} \\
\frac{\partial u}{\partial z}=0, & & |\tau| \leq \tau^{*}
\end{array}
$$

where $u$ is velocity in the $x$ direction, $\mu$ is the Bingham viscosity, $\tau$ is the shear stress, $\tau^{*}$ is the yield strength given in Equation (2), and the sign in $\left(\tau \pm \tau^{*}\right)$ is chosen to reduce the magnitude of the expression, because till deformation slows with increasing yield strength. The $x$ derivative of till pressure, $\partial P / \partial x$, must be balanced by a shear stress, $\tau$, in the $x$ direction parallel to the upper and lower surfaces of the till, such that

$$
\frac{\partial \tau}{\partial z}=\frac{\partial P}{\partial x} .
$$

(This derivation is modified from Turcotte and Schubert (1982, p. 234).) Integrating Equation (8) and noting that $\tau=0$ at $z=0$ gives

$$
\tau=z \frac{\partial P}{\partial x} .
$$

Substituting for $\tau$ in Equation (7) from Equation (9) and integrating with no-slip conditions (see discussion) at the upper and lower boundaries of the till, $z= \pm h / 2$, yields

$$
\begin{aligned}
u=-\frac{1}{\mu}\left\{\frac{1}{2} \frac{\partial P}{\partial x}\left[\left(\frac{h}{2}\right)^{2}-z^{2}\right]\right. & \left. \pm \tau^{*}\left(\frac{h}{2}-|z|\right)\right\} \\
z^{*} & \leq|z| \leq h / 2
\end{aligned}
$$




$$
\begin{aligned}
u=-\frac{1}{\mu}\left\{\frac{1}{2} \frac{\partial P}{\partial x}\left[\left(\frac{h}{2}\right)^{2}-z^{* 2}\right]\right. & \left. \pm \tau^{*}\left(\frac{h}{2}-z^{*}\right)\right\} \\
0 & \leq|z|<z^{*}
\end{aligned}
$$

where the sign preceding $\tau^{*}$ is negative if $\partial P / \partial x>0$ and positive if $\partial P / \partial x<0$; a rigid plug occurs between $\pm z^{*}$ given by

$$
z^{*}=\left|\tau^{*}\left(\frac{\partial P}{\partial x}\right)^{-1}\right|
$$

Averaging Equation (10) over the till thickness yields the till flux, $h \bar{u}$, as

$$
h \bar{u}=-\frac{1}{\mu}\left\{\frac{h^{3}}{12} \frac{\partial P}{\partial x} \pm\left[\frac{\tau^{*} h^{2}}{4}-\frac{\tau^{* 3}}{3}\left(\frac{\partial P}{\partial x}\right)^{-2}\right]\right\} .
$$

In the absence of till sources, continuity for till (which I assume to be incompressible) gives

$$
\frac{\partial(h \bar{u})}{\partial x}=-\dot{h}
$$

where $\dot{h}$ is the rate of change of till thickness with time. If ice and till maintain contact, then $\dot{h}$ can be estimated following Walder (1986), who approximated the creep closure of a subglacial cavity containing a low-viscosity fluid (water) using the Nye (1953) solution for closure of channels with circular cross-sections. Making the same approximation here (where the "cavity" is that part of the till layer undergoing creep thinning) yields

$$
-\dot{h}=K_{1} h\left(P_{\mathrm{i}}-P\right)^{n}
$$

where $n=3$ is the exponent for power-law creep of ice; the constant $K_{1}=A n^{-n}$, with $A$ the usual pre-factor for power-law creep of ice.

Differentiating Equation (12) with respect to $x$, equating to Equation (14) and solving with $\tau^{*}, \mu, K_{1}$ and $n$ assumed independent of $x$ yields

$$
\begin{gathered}
\left\{h^{3} \pm\left[2 \tau^{*}\left(\frac{\partial P}{\partial x}\right)^{-1}\right]^{3}\right\} \frac{\partial^{2} P}{\partial x^{2}}+\left(3 h^{2} \frac{\partial P}{\partial x} \pm 6 \tau^{*} h\right) \frac{\partial h}{\partial x} \\
+12 \mu K_{1} h\left(P_{\mathrm{i}}-P\right)^{n}=0 .
\end{gathered}
$$

To study the behavior of this system, consider introduction of a steady channel at $P_{\mathrm{w}}$ to a glacier bed with a uniform deforming till of thickness $h_{0}$ at time $t=0$, with the requirements that the till deforms toward the channel and that the ice and till remain in contact. The till pressure must rise to the ice-overburden pressure at the limit of till creep, $x^{*}$. Till creep must drop to zero at $x^{*}$ to maintain ice-till contact because the driving stress for downward ice creep drops to zero there. The boundary and initial conditions then are:

$$
\begin{gathered}
h(x, t=0)=h_{0} \\
P(x=0, t)=P_{\mathrm{w}} \\
P\left(x=x^{*}, t\right)=P_{\mathrm{i}}
\end{gathered}
$$

$$
\frac{\partial P}{\partial x}\left(x=x^{*}, t\right)=\frac{2 \tau^{*}}{h} .
$$

Notice that $x^{*}$ is time-dependent and determined by the requirements of till creep and ice-water contact. The system (15) and (16) can be solved numerically. Also, the condition (16b) of constant water pressure $P_{\mathrm{w}}$ at $x=0$ causes Equation (14) to integrate to

$$
\begin{gathered}
h(x=0)=h_{0} \exp \left(-\frac{t}{\theta}\right) \\
\frac{1}{\theta} \equiv K_{1}\left(P_{\mathrm{i}}-P_{\mathrm{w}}\right)^{n}
\end{gathered}
$$

independent of till properties.

For demonstration purposes, I will consider behavior of a $1 \mathrm{~m}$ thick till layer adjacent to a steady, water-filled Röthlisberger (1972) channel with radius $r=1 \mathrm{~m}$, and a $0.1 \mathrm{~m}$ thick till layer adjacent to a channel with $r=0.1 \mathrm{~m}$. For these cases, I assume that ice-water interactions control water pressures in channels and that the potential gradients driving water flow along the channels are $\psi=1000 \mathrm{~Pa} \mathrm{~m}^{-1}$ or $\psi=20 \mathrm{~Pa} \mathrm{~m}^{-1}$, values that might occur beneath a mountain glacier (labeled $\mathrm{M}$ in the figures) and beneath a low-profile ice stream draining a large ice sheet ( $\mathrm{S}$ in the figures), respectively, if the water table were parallel to the ice surface. Steady Röthlisberger channels with physical constants and roughness recommended by Weertman (1972) would then have the effective pressures listed in Table 1, ranging from a few bars to a few tens of bars. (The reader can test any combination of potential gradient, $\psi$, and radius, $r$, for turbulent flow in Röthlisberger channels using

$$
P_{\mathrm{i}}-P_{\mathrm{w}}=1.7 \times 10^{5} \psi^{1 / 2} r^{2 / 9} \mathrm{~Pa}
$$

where the numerical values recommended by Weertman (1972) have been adopted.)

From Equation (17), thinning of till at the ice-till interface is independent of till properties. Taking $n=3$ and $K_{1}=2 \times 10^{-25} \mathrm{~Pa}^{-3} \mathrm{~s}^{-1}\left(A=5 \times 10^{-24} \mathrm{~Pa}^{-3} \mathrm{~s}^{-1}\right)$, the response times, $\theta$, range from $10^{-3} \mathrm{a}\left(3.0 \times 10^{4} \mathrm{~s}\right)$ to $1.6 \mathrm{a}$ $\left(5.0 \times 10^{7} \mathrm{~s}\right)$ (see Table 1$)$. The continuum approximation must break down when the thickness reaches some "typical" clast height, which will depend on the till grain-size distribution and probably is of the order of $1-100 \mathrm{~mm}$. If that height is $10 \mathrm{~mm}$, then for the examples in Table 1 it is reached in about $1.5 \mathrm{~d}$ to $3.7 \mathrm{a}$. This is an estimate of the time required for a channel to become isolated from till creep from an adjacent deforming layer.

Away from the channel, calculation of the time evolution of till thickness and till supply to the channel requires specification of a Bingham viscosity and yield strength. I test till viscosities $\mu=10^{10} \mathrm{Pas}$ (low viscosity; $\mathrm{L}$ in figures), a possible value for till beneath Ice Stream B (Alley and others, 1987b), and $\mu=10^{12} \mathrm{Pas}$ (high viscosity; $\mathrm{H}$ in figures), which may be more appropriate for lowered pore-water pressures in till adjacent to a channel, especially in the mountain-glacier case. To test dependence on yield strength, I start with the same yield strength as in the perfect-plasticity solution and 
Table 1. Response times and rates of till supply per unit length of channel for examples considered in the text

\begin{tabular}{|c|c|c|c|c|c|c|c|}
\hline $\begin{array}{l}\text { Channel } \\
\text { radius }\end{array}$ & $\begin{array}{l}\text { Potential } \\
\text { gradient }\end{array}$ & $\begin{array}{l}\text { Pressure } \\
\text { drop }\end{array}$ & $\begin{array}{c}\text { Response } \\
\text { time }\end{array}$ & $\begin{array}{c}\text { Till } \\
\text { thickness }\end{array}$ & $\begin{array}{c}\text { Till } \\
\text { viscosity }\end{array}$ & $\begin{array}{c}\text { Initial } \\
\text { till } \\
\text { supply }\end{array}$ & $\begin{array}{c}\text { Figure } \\
\text { code }\end{array}$ \\
\hline$r$ & $\psi$ & $P_{\mathrm{i}}-P_{\mathrm{w}}$ & $\theta$ & $h_{0}$ & $\mu$ & & \\
\hline $\mathrm{m}$ & $\mathrm{Pa} \mathrm{m}^{-1}$ & $\mathrm{~Pa}$ & a & $\mathrm{m}$ & Pas & $\mathrm{m}^{3} \mathrm{a}^{-1} \mathrm{~m}^{-1}$ & \\
\hline 1 & 20 & $7.8 \times 10^{5}$ & 0.33 & 1 & $10^{10}$ & 3.7 & LS \\
\hline 1 & 20 & $7.8 \times 10^{5}$ & 0.33 & 1 & $10^{12}$ & 1.5 & HS \\
\hline 1 & 1000 & $5.5 \times 10^{6}$ & $9.5 \times 10^{-4}$ & 1 & $10^{10}$ & 709 & LM \\
\hline 1 & 1000 & $5.5 \times 10^{6}$ & $9.5 \times 10^{-4}$ & 1 & $10^{12}$ & 90 & HM \\
\hline 0.1 & 20 & $4.6 \times 10^{5}$ & 1.6 & 0.1 & $10^{10}$ & 0.0077 & LS \\
\hline 0.1 & 20 & $4.6 \times 10^{5}$ & 1.6 & 0.1 & $10^{12}$ & 0.0043 & HS \\
\hline 0.1 & 1000 & $3.2 \times 10^{6}$ & $4.8 \times 10^{-3}$ & 0.1 & $10^{10}$ & 1.9 & LM \\
\hline 0.1 & 1000 & $3.2 \times 10^{6}$ & $4.8 \times 10^{-3}$ & 0.1 & $10^{12}$ & 0.46 & $\mathrm{HM}$ \\
\hline
\end{tabular}

then lower it in order-of-magnitude steps. Results include:

Decreasing the till viscosity increases the initial rate of till supply to the channel (Fig. 2; Table 1).

Increasing the till thickness increases the initial rate of till supply to the channel (Table 1).

Till thinning is fastest adjacent to the channel (Figs 2 and 3$)$.

The maximum rate of till supply to the channel occurs at $t=0$ (Fig. 4).

For given till properties, lowering the water pressure in the channel increases the driving stress for till creep and thus the rate of till supply (Table 1).

The maximum distance, $x^{*}$, from which creep can occur decreases with increasing time (Fig. 3) because the fastest thinning occurs at the channel, and the pressure gradient driving till creep must steepen to force till through the thinning layer there.

Results are only weakly sensitive to the assumed till yield strength for the assumed till viscosities (Fig. 5).

This last point is especially important. Creep to the channel is driven by $P_{\mathrm{i}}-P_{\mathrm{w}}$, and is opposed by the yield strength and the viscosity of the till. Far from the channel where creep is slow, the magnitude of the pressure gradient in the till is that needed to overcome the yield strength; near the channel creep is faster, and the magnitude of the pressure gradient must increase to overcome the viscous forces (Fig. 2a). In all cases considered here except the low-viscosity, ice-stream case at short times (LS in Fig. 2), the major control near the channel is viscosity. And as time passes and the pressure gradient near the channel increases to force till through the thinning layer there, the yield strength becomes insignificant in all cases considered here. Thus, although the yield strength is critical to setting the length scale of failure in the perfect-plasticity model, a low yield strength will not produce significant time-dependent creep from long distances if viscosity is significant. This result is quite robust for the high-viscosity cases but less so for the lowviscosity, ice-stream case; clearly, if viscosity were much lower than assumed here, the results would be more sensitive to changes in the yield strength.

\section{DISCUSSION}

Many complexities are omitted from the model here. For example, water pressures undergo large variations in channels connected to the ice surface. This will contribute to till strength being a complex function of time and distance from a channel, depending on the coupled behavior of till deformation and porous flow through the till (Shoemaker, 1986). The ice pressure on the sediment will vary with distance from a channel owing to the bridging effect modeled by Weertman (1972). Complications such as these should change the exact values of numerical calculations here, but should not affect the basic result that significant till strength or viscosity will limit the creep of till to channels.

The channel form shown in Figure 1 clearly is an oversimplification (Walder and Fowler, 1989; Hooke and others, 1990). At the water-till interface, both the bulk pressure on the till, $P$, and the pore-water pressure in the till, $P_{\mathrm{p}}$, approach the water pressure in the channel, $P_{\mathrm{w}}$, so that the effective pressure, $N \equiv P-P_{\mathrm{p}}$, approaches zero. If till cohesion is small, then the till will have little strength there (Equation (2)). A vertical face such as shown in Figure 1 then would collapse under its own weight, causing channels to be broad and shallow. Such behavior has been predicted theoretically (Walder and Fowler, 1989) and supported by field data (Hooke and others, 1990). The exact form of the channel is a complicated problem still not solved (Walder and Fowler, 1989), but schematically it might resemble Figure 6 .

For the geometry of Figure 6, calculations following 

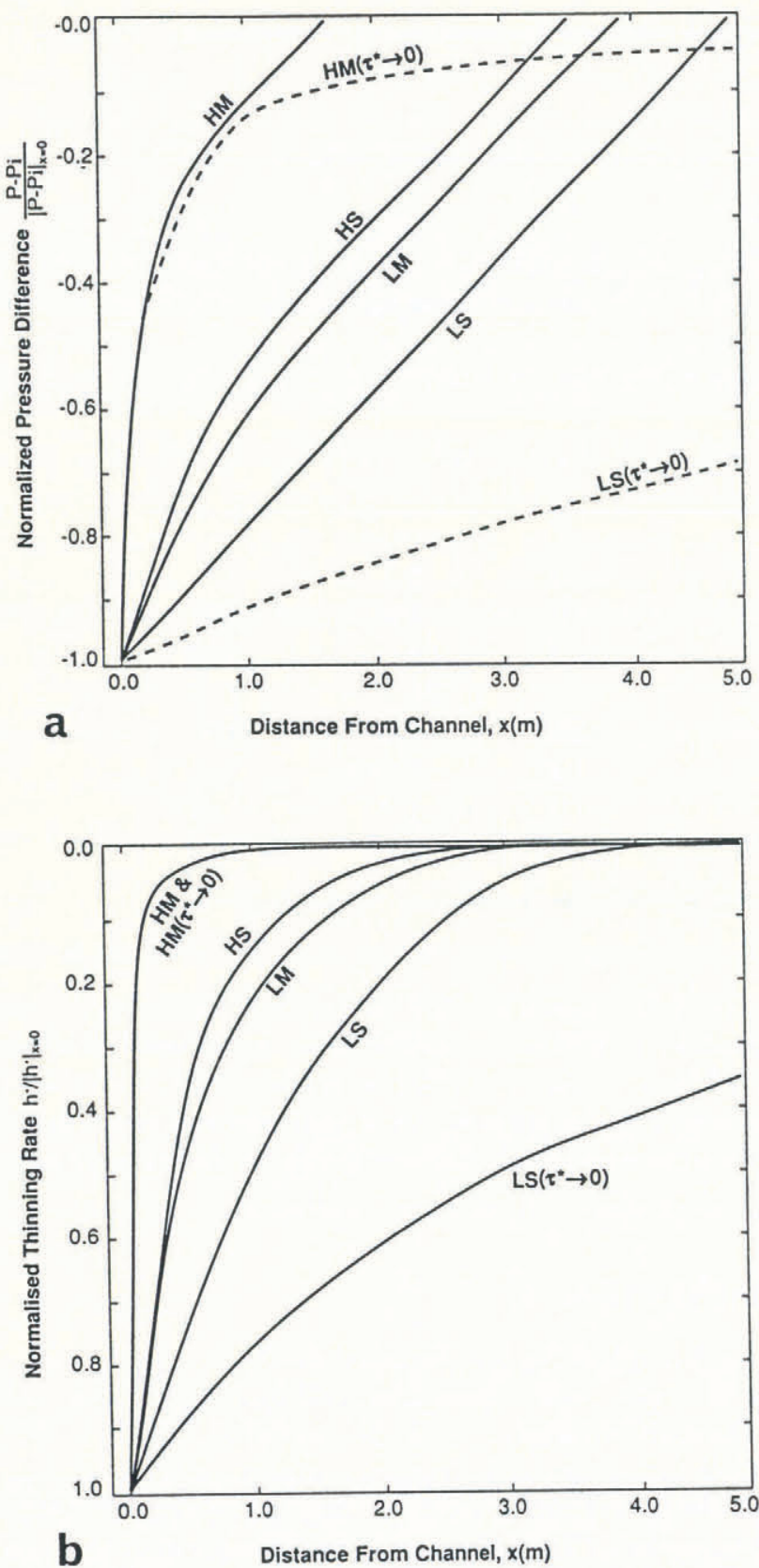

Fig. 2. Initial distributions of pressure, $P$, and rate of thickness change, $\dot{h}$, in $1 \mathrm{~m}$ thick subglacial till at onset of time-dependent creep to a $1 \mathrm{~m}$ radius channel penetrating the till. Cases shown are: $M$, mountain glacier; $S$, ice stream and $H$, high viscosity; $L$, low viscosity, as described in the text and Table 1. Solid lines are for a Bingham substance with yield strength given in Equation (5) with $\tan \phi=$ 0.2 (LS, HS, LM, HM cases); dashed lines are behavior in limit of yield strength reduced toward zero (LS, HM cases). (a) Initial pressure distribution. Pressures everywhere are $\leq P_{\mathrm{i}}$, the ice pressure, and are plotted normalized by the magnitude of the pressure difference at the channel, $\left|P-P_{\mathrm{i}}\right|_{x=0}$ or $\left|P_{\mathrm{w}}-P_{\mathrm{i}}\right|$. (b) Initial rate of thickness change. Rate of change, $\dot{h}$, is normalized by the magnitude of this rate at the channel, $|\dot{h}|_{x=0}$, for the pressure distributions and cases shown in Figure 2a. The HM cases for significant and zero yield strength are indistinguishable at this scale.
Shoemaker (1986) show that pore-water flow through the creeping till will, within a few hours, lower $P_{\mathrm{p}}$ more than $P$ is lowered by creep failure of the till as modeled here, causing $N$ to increase away from the channel in the creeping till. (Assuming a till permeability of $\approx 10^{-6} \mathrm{~m} \mathrm{~s}^{-1}$ (Boulton and others, 1974), Shoemaker (1986) showed that a sinusoidal variation in $P_{\mathrm{w}}$ with an amplitude of $1 \mathrm{~d}$ is transmitted to the pore water in the till with a $1 / e$ distance of $16 \mathrm{~m}$, compared to significant reduction in $P$

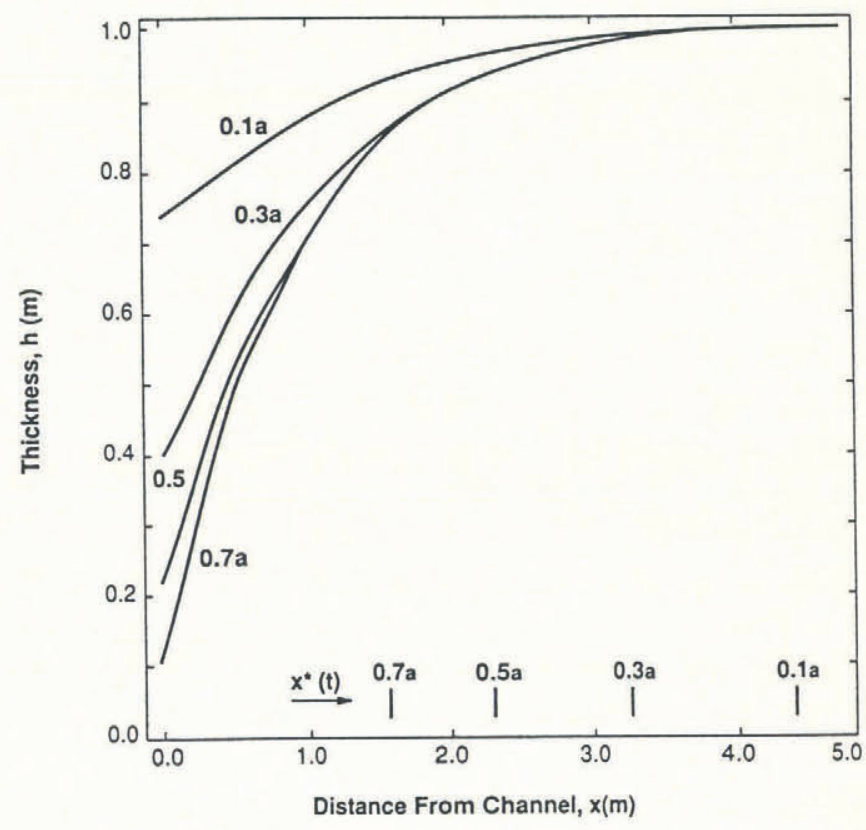

Fig. 3. Time evolution of till thickness for the low-viscosity, ice-stream (LS), $1 \mathrm{~m}$ case with yield strength given by Equation (5) and $\tan \phi=0.2$. The thickness is plotted for times $t=0,0.1,0.3,0.5$ and $0.7 \mathrm{a}$, and the distance from which creep is occurring at each time, $x^{*}(t)$, is shown.

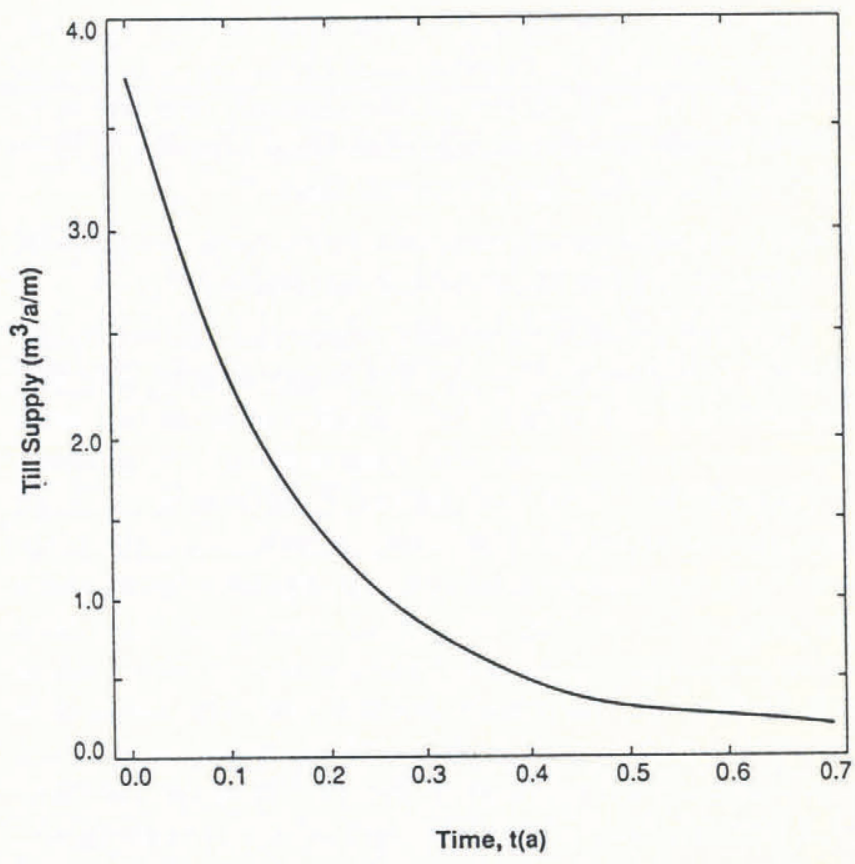

Fig. 4. Time evolution of till flux to channel for the example shown in Figure 3. 


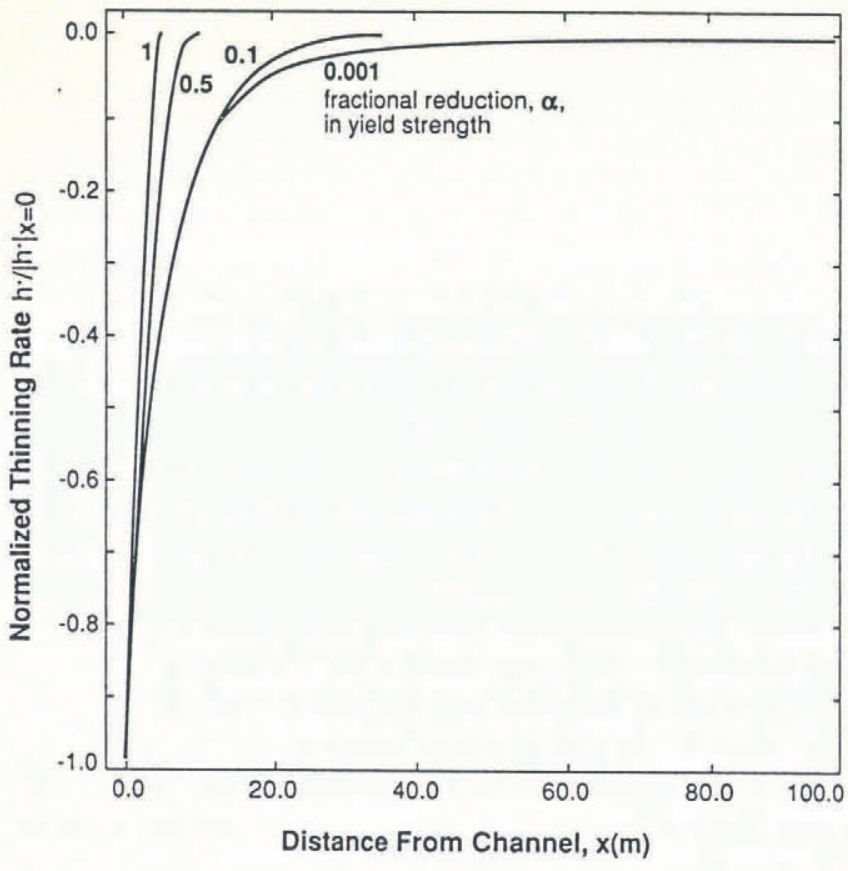

Fig. 5. Dependence of initial till thinning rate on yield strength, for creep of a $1 \mathrm{~m}$ thick till layer to a $1 \mathrm{~m}$ radius channel in the low-viscosity, ice-stream case (LS), which is the case considered here where yield strength is most important. The yield strength for each curve is $\alpha \tau^{*}$, where $\tau^{*}$ is calculated from Equation (5) with $\tan \phi=0.2$, and the curves are labeled with $\alpha$. The catchment widths, $x^{*}$, are $4.95 m$ for $\alpha=1,9.4 m$ for $\alpha=0.5,35 m$ for $\alpha=0.1,142 m$ for $\alpha=0.01$ (not shown) and $484 \mathrm{~m}$ for $\alpha=0.001$, and continue to widen with decreasing $\alpha$ toward zero. However, thinning rates for $\alpha<0.01$ are indistinguishable from $\alpha=0.01$ on the scale plotted here, and thinning rates in excess of $10 \%$ of the maximum value are indistinguishable for $\alpha \leq 0.1$.

extending only $5 \mathrm{~m}$ or less in almost all of the cases considered here; Fig. 2.) This will cause the till in the wedge at $x<0$ in Figure 6 to have strength from internal friction as well as cohesion, and will require a pressure gradient in the till to cause creep through the wedge to the channel. Then at $x=0$, the edge of the channel, $P>P_{\mathrm{w}}$ in the till. The driving force for till creep to the channel in this case is less than calculated above, and the catchment area for significant till creep is less than calculated above, strengthening my conclusions. The geometry of Figure 6 would increase the time needed for isolation of the channel from the till compared to the geometry of Figure 1, but faster thinning at $x=0$ than at $x>0$ still would occur in the Figure 6 case, eventually isolating the channel from the till. I therefore feel justified in ignoring the interesting but difficult question of channel shape.

The results here require that subglacial till has a significant yield strength or a significant viscosity. Recent work by Kamb $(1990,1991)$ suggests that subglacial till approaches perfect plasticity (strain rate proportional to stress raised to a large power, perhaps 100), based on

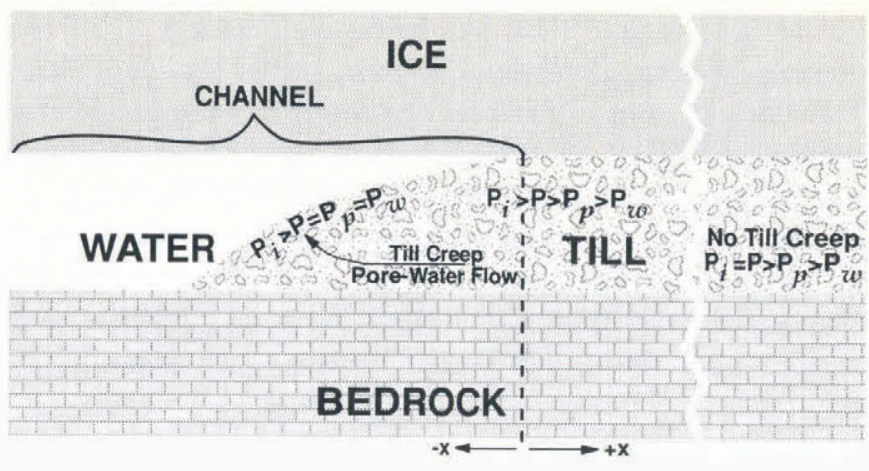

Fig. 6. Cartoon of the possible geometry and pressure relations if till has low cohesion and the till-water face collapses.

unconfined testing of till and on results from soil mechanics. One might suggest that for the situation modeled here, if the basal shear stress of the ice exceeded the yield strength of a perfectly plastic till, and if the yield strength were a scalar rather than a tensor property of till, then the till would offer almost no resistance to creep to the channel.

I consider this scenario to be unlikely for several reasons. First, the high stress exponent assumed by Kamb $(1990,1991)$ does not accord with the (limited) available data on subglacial deformation. If till follows a linearviscous or other creep law with a small stress exponent, the thickness of till deformed by the basal shear stress of the ice can be relatively large, whereas increase of the stress exponent toward the infinite value in perfect plasticity will collapse the zone of significant deformation toward a single surface (e.g. Turcotte and Schubert, 1982 , p. 318). The available data (Boulton and Hindmarsh, 1987; Blake and Clarke, 1989; Meier, 1989) show a broad zone of deformation in subglacial till, consistent with a low stress exponent (including linear-viscous behavior) but inconsistent with a high stress exponent (Alley, 1989b). A larger data set might find perfectly plastic behavior (and indeed, localized deformation occurs in the deforming till studied by Boulton and Hindmarsh (1987), although distributed deformation dominates), but a small stress exponent seems a better model now.

Secondly, deformation of till aligns clasts, suggesting the possiblity of a tensor yield strength (Murray and Dowdeswell, 1990). Shear deformation along a surface (such as might occur in a perfectly plastic till) typically produces a striated or slickensided surface that is smooth parallel to the motion but rough transverse to the motion. If deformation were occurring along ice flow, such a surface probably would have significant strength against initiation of transverse creep to a channel.

Even if the till were a perfect plastic with a scalar yield strength, however, the conclusions here would be valid. Deformation of perfectly plastic till by the basal shear stress of the ice should cause failure on a single surface, probably at the top of the till, but creep of till to a channel requires failure at the top and bottom of the till. A pre-existing failure surface would reduce the resistance to creep toward a channel, and increase the distance from which creep could occur, by a factor of two 
$\left(x^{*} \approx 10 h_{\mathrm{w}}\right.$ rather than $5 h_{\mathrm{w}}$ in Equation $\left.(6 \mathrm{~b})\right)$. The till catchment area then would be $10 \mathrm{~m}$ rather than $5 \mathrm{~m}$ for a $1 \mathrm{~m}$ thick till, not a large enough difference to change the conclusions here. If the till had a high stress exponent (or if till followed some other flow law but slip occurred on its upper and lower boundaries rather than having no-slip boundaries), the till flux would be increased by some geometric factor over that shown in Figure 4 and Table 1, but this is not critical to the conclusions here.

\section{CONCLUSIONS}

Despite numerous uncertainties, I believe that the results here are quite robust at the order-of-magnitude level. Low-pressure channels do exist subglacially, and till creep has been induced into one such channel (Boulton, 1976), driven by the pressure drop into it. Such creep, if it occurs, will be resisted by the viscosity plus any yield strength of the till. The resulting force balance is expressed in Equation (1), if the strength $\tau^{*}$ is understood to be the total resistance to significant creep, and the distance $x^{*}$ is understood to be the maximum distance for significant creep. Data from subglacial till shear along ice flow suggest that $\tau^{*}$ then is a few tenths of a bar (e.g. Engelhardt and others, 1978; Alley and others, 1987b; Boulton and Hindmarsh, 1987). If the pressure drop into the channel is a few bars, and the till thickness is a few tenths of a meter, then $x^{*}$ can be no more than about ten times the till thickness. This can be increased substantially only if both till viscosity and till yield strength for creep to a channel are small compared to values used here. (The values used here are in accord with the best available data; however, the data are sufficiently limited that it remains possible that the values used here are substantially in error at some times or places.) The calculations here are valid for linearviscous, Bingham and perfectly plastic models, so uncertainties in the stress exponent for till deformation do not affect my results.

If a channel can remove the till supplied to it and remain open (Alley, 1989a), then the till will thin in the narrow zone of creep near the channel. This will isolate the channel from till farther away, often in a single melt season. The observed coexistence of lowpressure channels and thin deforming till layers then is explained provided spacings between low-pressure channels are $>\approx 10 \mathrm{~m}$ and lateral migration of channels is not too fast.

If my results are correct, then a subglacial deforming till should be thin or absent very near (within one or a few meters of) any long-lived channel. This clearly can be tested, although the test might be technically difficult. The thinning of till near channels calculated here will affect the transmission of water-pressure fluctuations from a channel to the rest of the bed, and will affect the spatial distribution of basal drag on ice flow, with possible effects on ice dynamics.

\section{ACKNOWLEDGEMENTS}

This research was supported in part by the U.S. National Science Foundation, Division of Polar Programs, under grants DPP-8716016 and DPP-8915995. I thank A.C.
Fowler, D.R. MacAyeal, C.F. Raymond, J.S. Walder and I. M. Whillans for helpful suggestions.

\section{REFERENCES}

Alley, R.B. 1989a. Water-pressure coupling of sliding and bed deformation: I. Water system. J. Glaciol., 35(119), 108-118.

Alley, R.B. 1989b. Water-pressure coupling of sliding and bed deformation: II. Velocity-depth profiles. J. Glaciol., 35(119), 119-129.

Alley, R. B., D. D. Blankenship, C. R. Bentley and S.T. Rooney. 1987a. Till beneath Ice Stream B. 3. Till deformation: evidence and implications. J. Geophys. Res., 92(B9), 8921-8929.

Alley, R.B., D. D. Blankenship, S. T. Rooney and C. R. Bentley. 1987b. Till beneath Ice Stream B. 4. A coupled ice-till flow model. J. Geophys. Res., 92(B9), 8931-8940.

Blake, E.W. and G.K.C. Clarke. 1989. In situ bed strain measurements beneath a surge-type glacier. [Abstract.] Eos, 70(43), 1084.

Boulton, G.S. 1976. The origin of glacially fluted surfaces - observations and theory. J. Glaciol., 17(76), 287309.

Boulton, G. S. and R. C. A. Hindmarsh. 1987. Sediment deformation beneath glaciers: rheology and geological consequences. J. Geophys. Res., 92(B9), 9059-9082.

Boulton, G. S., D. L. Dent and E. M. Morris. 1974. Subglacial shearing and crushing, and the role of water pressures in tills from south-east Iceland. Geogr. Ann., 56A(3-4), 135-145.

Clarke, G. K. C. 1987. Subglacial till: a physical framework for its properties and processes. J. Geophys. Res., 92(B9), 9023-9036.

Engelhardt, W. F., W. D. Harrison and B. Kamb. 1978. Basal sliding and conditions at the glacier bed as revealed by bore-hole photography. J. Glaciol., 20(84), 469-508.

Hooke, R. LeB., T. Laumann and J. Kohler. 1990. Subglacial water pressures and the shape of subglacial conduits. J. Glaciol., 36(122), 67-71.

Kamb, B. 1990. Rheological nonlinearity and flow instability in the deforming-bed mechanism of ice-stream motion. [Abstract.] Eos, 71(43), 1302.

Kamb, B. 1991. Rheological nonlinearity and flow instability in the deforming-bed mechanism of ice-stream motion. J. Geophys. Res., 96, 16,585-16,595.

Meier, M.F. 1989. Relation between water input, basal water pressure, and sliding of Columbia Glacier, Alaska, U.S.A. (Abstract.) Ann. Glaciol., 12, 214215.

Murray, T. and J. A. Dowdeswell. 1990. The effect of subglacial conditions on sediment deformation and rheology. [Abstract.] Eos, 71(43), 1314.

Nye, J.F. 1953. The flow law of ice from measurements in glacier tunnels, laboratory experiments and the Jungfraufirn borehole experiment. Proc. R. Soc. London, Ser. A, 219(1139), 477-489.

Röthlisberger, H. 1972. Water pressure in intra- and subglacial channels. J. Glaciol., 11(62), 177-203.

Shoemaker, E. M. 1986. Subglacial hydrology for an ice 
sheet resting on a deformable aquifer. J. Glaciol., 32(110), 20-30.

Turcotte, D.L. and G. Schubert. 1982. Geodynamics. New York, John Wiley and Sons.

Walder, J.S. 1986. Hydraulics of subglacial cavities. J. Glaciol., 32(112), 439-445.

Walder, J.S. and A. C. Fowler. 1989. Channelized subglacial drainage over a deformable bed. [Abstract.]
Eos, 70(43), 1084.

Weertman, J. 1972. General theory of water flow at the base of a glacier or ice sheet. Rev. Geophys. Space Phys., 10(1), 287-333.

The accuracy of references in the text and in this list is the responsibility of the author, to whom queries should be addressed.

MS received 13 November 1990 and in revised form 2 July 1991 